\title{
Percepciones sociales del proceso de municipalización del agua potable en comunidades periurbanas de León, Guanajuato
}

\section{Social Perceptions about the Drinking Water Municipalization Process in Peri-urban Communities in León, Guanajuato}

\author{
Jennifer Hernández González* (iD http://orcid.org/0000-0001-6837-5149 \\ Daniel Tagle Zamora** (D) https://orcid.org/0000-0002-6203-7429
}

\begin{abstract}
Resumen
El objetivo de este artículo consiste en identificar las percepciones sociales del proceso de municipalización del servicio de agua potable en comunidades periurbanas que tenían el control de la gestión del recurso. Se consideraron tres comunidades en León, Guanajuato: La Laborcita, que mantiene la gestión del comité rural del agua porque rechazó su incorporación a la municipalización; Ladrilleras del Refugio, que incorporó su gestión en 20I8; y Loza de los Padres, que en la actualidad presenta conflictos por las iniciativas de incorporación. Se utilizó una metodología cualitativa, a través de entrevistas en profundidad y observación no participante que permitieron identificar los argumentos a favor y en contra sobre la municipalización del servicio de agua potable. La selección de casos de estudio no permite analizar lo que ocurre en aquellas comunidades que se encuentran en el área periurbana colindante al resto de los municipios de la zona metropolitana de León ni refleja las problemáticas de las comunidades rurales alejadas del área urbana. Los resultados muestran que la incorporación de la gestión del agua de las comunidades periurbanas al sistema urbano depende del nivel de confianza que las comunidades tienen tanto de sus propios comités de agua como del organismo operador de agua potable del municipio.

Palabras clave: gestión del agua; gestión comunitaria; periurbanización; percepción social; Guanajuato.
\end{abstract}

\begin{abstract}
The purpose of this article is to identify the social perceptions about municipalizing the drinking water service in peri-urban communities that used to manage it. Three communities were considered in León, Guanajuato: La Laborcita, which preserves the rural management of water because they denied the incorporation to the urban management; Ladrilleras del Refugio, which was incorporated in 20I8; and Loza de los Padres, which is still in conflict due to the incorporation process. A qualitative methodology was used through in-depth interviews and non-participant observation to understand pros and cons about drinking water service municipalization. This case studies selection cannot allow analyzing what happen in peri-urban communities in the rest of municipalities of the metropolitan area of León, furthermore it cannot show the reality of the rural communities away from urban areas. The evidence shows that the incorporation of rural water management to urban water management depends on the trust communities have on their own rural water committees and on the municipality urban water operator.

Keywords: water management; community management; peri-urbanization; social perception; Guanajuato.
\end{abstract}

Cómo citar: Hernández González, J., y Tagle Zamora, D. (2020). Percepciones sociales del proceso de municipalización del agua potable en comunidades periurbanas de León, Guanajuato. región y sociedad, 32, e I257. doi: I 0.22 | 98/rys2020/32/ | 257

* Autora para correspondencia. El Colegio de México. Avenida 20 de noviembre Núm. 133, interior 9, colonia Centro, alcaldía Cuauhtémoc, C. P. 06090 , Ciudad de México.Correos electrónicos: jehernandez@colmex.mx; jenni_dia@hotmail.com

** Universidad de Guanajuato, Campus León, Departamento de Estudios Sociales. Blvd. Puente Milenio, fracción del Predio de San Carlos Núm. 1001, C. P. 37670, León, Guanajuato, México. Correos electrónicos: datagle@yahoo.com.mx; datagle@ugto.mx

Recibido: 30 de octubre de 2019

Aceptado: 11 de marzo de 2020

Liberado: 14 de abril de 2020 


\section{Introducción}

El desarrollo económico en la región del Bajío guanajuatense promueve un proceso dinámico de urbanización metropolitana que se expande sobre el suelo rural contenido en el territorio (Álvarez, 2016; Rodríguez y Caldera, 2013; Rodríguez, Caldera y Tagle, 2016). ${ }^{1}$ En la zona metropolitana de León $(\mathrm{ZML})^{2}$ destaca el caso de la ciudad de León por su acelerado crecimiento urbano y económico a partir de la década de 1990 (García, 2019). Este crecimiento ha implicado, entre otras cosas, el aumento multidimensional de la demanda de agua en una región que padece estrés hídrico (Sistema de Agua Potable y Alcantarillado de León [SAPAL], 2012; Tagle, 2016).

En la actualidad, el abastecimiento del agua urbana en León depende de la extracción de agua subterránea (SAPAL, 2012). De forma paralela, el gobierno local mantiene una apuesta institucional en dos proyectos que pretenden garantizar la disponibilidad futura del agua para el sostenimiento económico de esta región: el primero tiene que ver con el trasvase pactado con el estado de Jalisco mediante la presa El Zapotillo; el segundo es la incorporación de pozos de abastecimiento -que en el presente se gestionan bajo un esquema comunitario- al sistema de gestión urbana mediante la municipalización del servicio de agua potable de las comunidades rurales (Hernández, 2019).

Ambas apuestas tienen un elevado componente político-económico; en especial la de El Zapotillo, que desde su puesta en marcha como proyecto en la década de 2000 desató un conflicto de alcances internacionales, asociado con los elevados costos financieros y sociales implicados en su desarrollo (Barkin, 2014; Caldera, 2011; Caldera y Tagle, 2015; Lozano, 2014; Pacheco-Vega, 2017). Se suma al conflicto la incertidumbre respecto a la continuidad del proyecto, toda vez que el responsable del Ejecutivo federal, Andrés Manuel López Obrador, ha pedido que las autoridades de los estados de Jalisco y de Guanajuato, junto con las comunidades implicadas, lleguen a un acuerdo a partir del cual se diseñen estrategias alternas para el abastecimiento de agua, en cantidad y en calidad, para ambos territorios.

Por otro lado, la municipalización del servicio de agua potable es un proceso de trasferencia negociada del agua de las comunidades rurales que se lleva a cabo mediante el traspaso de la gestión y de la infraestructura al municipio. No obstante, la municipalización, como estrategia de abastecimiento, no ha tenido la misma proyección en el ámbito político como sí lo ha tenido en todo momento la presa El Zapotillo. En este caso, la dinámica socioeconómica imperante en la región para la década 2010 ha propiciado una serie de cambios en el territorio a consecuencia de la urbanización que a su vez incide en las prácticas

1 De ahí que la dinámica del también llamado corredor industrial del Bajío ha motivado la categorización de tres zonas metropolitanas desde la óptica del Instituto de Planeación del Estado de Guanajuato (IPLANEG), cuya gestión de recursos se vuelve importante para el sostenimiento de la actividad económica industrial proyectada en la región

2 Zona metropolitana de León: León, Silao, San Francisco del Rincón y Purísima del Rincón; zona metropolitana Irapuato-Salamanca (conformada por esas dos entidades); y la zona metropolitana Laja-Bajío: Celaya, Comonfort, Juventino Rosas, Villagrán, Cortázar, Jaral del Progreso, Tarimoro, Apaseo el Alto y Apaseo el Grande. 
rurales relacionadas con el uso y el manejo del agua. La franja periurbana de la ciudad de León está formada por una serie de comunidades rurales que han sostenido su crecimiento a la par de la ciudad, habiéndose mantenido principalmente de las actividades agrícola y ganadera (Bazant, 2015; García, 2010; Mata, 2009; Suárez, Martínez y García, 2015). Las condiciones de urbanización de los espacios rurales en el territorio metropolitano replantean las prácticas sociales de las comunidades, así como las representaciones que los habitantes construyen sobre sus recursos naturales. Estos últimos dos componentes influyen en la gestión del agua, en específico para el caso que aquí se estudia: ya sea en las necesidades de la administración, en los fundamentos de la distribución y del uso, así como en las tecnologías adoptadas para llevar a cabo dicha tarea.

La convivencia de diversas prácticas y representaciones en un territorio heterogéneo, como es el área periurbana de la zona metropolitana de León, conduce a la gestación de distintos tipos de conflictos socio-ambientales en la gestión comunitaria del agua. El análisis del conflicto permite entrever una tipificación de prácticas que se sostienen en torno a la administración y al uso del agua, tanto en comunidades rurales cuya gestión ha sido incorporada al organismo municipal, como en aquellas que se resisten a la dinámica de municipalización del agua.

Siguiendo esta línea de argumentación, el objetivo de la presente investigación es identificar las percepciones sociales que se desarrollan en el marco de la gestión comunitaria del agua a partir del planteamiento de la municipalización del servicio de agua potable en las comunidades periurbanas de León, Guanajuato. Se estudia el caso a partir del conocimiento de las condiciones que han llevado a los actores involucrados a tomar posturas a favor o en contra de la municipalización en las comunidades rurales La Laborcita, Ladrilleras del Refugio y Loza de los Padres en León, Guanajuato. El proceso de urbanización por el que atraviesan las comunidades ha inducido el avance de la incorporación municipal en la prestación de los servicios de agua potable y alcantarillado como una estrategia para el abastecimiento inmediato y futuro de la ciudad de León.

El documento se estructura de la siguiente manera: en la primera sección se aborda el planteamiento mediante el cual se realiza el análisis. Luego se describe la zona de estudio donde se desarrolla el proceso de municipalización del agua. En la tercera parte se consideran los aspectos metodológicos con los que se realiza la investigación. En la cuarta sección se describen el desarrollo y los resultados de la investigación. Al final se ofrecen las conclusiones.

\section{Marco conceptual}

Se toma el área metropolitana como escala de análisis, que en este caso permite replantear las relaciones entre los espacios urbanos y rurales contenidos en un mismo territorio. A partir del concepto de lo metropolitano se hace evidente que ambos espacios están imbricados y sus límites se vuelven difusos (Cruz, 2005), pues su relación ya no es de subordinación ni de oposición, sino de complementariedad. Puede decirse que la urbanización metropolitana es la 
expresión del nuevo orden económico global surgido a mediados del siglo XX (Alguacil, 2012).

El fenómeno de metropolización o la conformación de zonas, áreas y regiones metropolitanas, abre un nuevo capítulo a la forma en que se analiza, se clasifica y se ordena el territorio. Hay un consenso en torno a que la metropolización ocurre cuando una ciudad, en su proceso de expansión, rebasa sus límites político-administrativos para usar suelo de otros municipios, lo cual implica, además, una relación de coordinación entre más de un gobierno local. No se consideran zonas metropolitanas sólo los espacios físicos unidos y compactos, sino que también resaltan las relaciones de funcionalidad entre una ciudad y otra (Alguacil, 2012; Ávila, 2009; Garrocho, 2013; Ramírez, 2006; Sobrino, 2003 y 2011).

Otra característica de las zonas metropolitanas es la incorporación no sólo de las localidades urbanas, sino también de las localidades rurales ubicadas en la periferia de las ciudades centrales (Ávila, 2009). Esta nueva función enmarca una faceta de la relación entre lo urbano y lo rural, donde los espacios periféricos urbanos se vuelven el soporte del crecimiento metropolitano, pues son los espacios que permitirán la expansión de las ciudades que ahora se pueden considerar insostenibles, irreproducibles y vulnerables (Méndez, 2005; Ramírez, 2005 y 2006) debido al patrón de crecimiento ilimitado que consume y contamina recursos naturales y pone en riesgo las condiciones de vida de la población. Además, estos espacios periféricos no son homogéneos, sino que tienen marcadas diferencias geográficas y sociales que determinan el modo de vida de sus habitantes y la forma particular en que gestionan los recursos naturales.

Relación entre lo rural y lo urbano

La relación entre el campo y la ciudad está ubicada en un amplio debate, puesto que históricamente ambas han sido consideradas espacialidades antagónicas y opuestas. Esta conceptualización ha dejado de reflejar la relación entre ambos espacios una vez que se han materializado los efectos de las políticas neoliberales en el territorio, pues se han trasformado de manera profunda las funciones, las características y la relación entre ambos entornos. La nueva relación cada vez más estrecha entre el campo y la ciudad se debe a la flexibilización de los procesos productivos (Delgado, 2003). Se pueden entender lo rural y lo urbano como territorios integrados y heterogéneos, cuya relación se vuelve cada vez más difusa como resultado de los impactos que imprime la globalización al territorio y a causa de la diversidad de fenómenos que se manifiestan en él.

A pesar de estar sometidos a un mismo proceso de globalización, cada espacio geográfico adquiere una configuración propia (Grammont, 2005), pues ésta es resultado de "la interacción entre la dinámica capitalista global y las condiciones y respuestas de los actores locales” (Suárez, Martínez y García, 2015, p. 11). La expansión de las ciudades sobre el suelo rural ha favorecido el contacto de los modos de vida característicos de cada espacio y ha detonado respuestas particulares de los actores locales. 
Hay una diferencia cualitativa en la forma en que se ha expandido la ciudad sobre el campo, que pasó de ser centrípeta a centrífuga (Ramírez, 2005). Lo anterior da como resultado el desarrollo de nuevas formas de vida en torno a una nueva configuración del territorio: la forma de relación, de apropiación y de aprehensión (Ávila, 2005 y 2009). En el ejercicio de construcción de un lenguaje que permita comunicar y estudiar estas trasformaciones territoriales, resultado de la expansión metropolitana, nace el concepto de periurbanización o del espacio periurbano.

Se entiende la periurbanización como el espacio que contrasta físicamente la continuidad entre la vida rural y la concentración urbana. Es un espacio de transición que se manifiesta en la constitución de coronas o espacios periféricos concéntricos (Ávila, 2009) como resultado de la urbanización contemporánea. En él se concentra una nueva forma de vida, animada por los ritmos de la ciudad, por sus expresiones políticas y culturales y por la predominancia de las actividades productivas de corte urbano. La periurbanización, además de sus consecuencias territoriales, genera un intenso intercambio cultural entre lo rural y lo urbano y modifica bastante los modos de vida de la población: las características de su movilidad, la accesibilidad a los centros urbanos, la infraestructura para el trasporte urbano y suburbano y la elección del lugar de residencia (Ávila, 2005).

En el espacio periurbano se pueden identificar particularidades que ayudan a comprender la nueva relación que se vive entre el campo y la ciudad desde una escala metropolitana. Se cuenta con una serie de actores urbanos y rurales que al convivir en un mismo territorio reelaboran sus identidades y refuncionalizan sus prácticas sociales (Canabal, 2005; Cruz, 2005), pues “los cambios en la realidad rural equivalen a aquellos experimentados por sus protagonistas concretos, porque es a través del devenir cotidiano de sus vidas como se construye la historia" (Méndez, 2005, p. 88).

La urbanización metropolitana es resultado de la flexibilización de los procesos productivos la cual permite relocalizar eslabones de la cadena de producción en aquellos territorios que ofrecen las condiciones ideales para maximizar las ganancias. En esta medida, los espacios rurales, como proveedores de recursos, son el sostén del crecimiento y del desarrollo del sistema urbano con las consecuencias sobre el estilo de vida de sus habitantes. Estas condiciones pueden identificarse en el caso concreto del Bajío guanajuatense, que es el marco que sirve de contexto para problematizar los efectos de la urbanización metropolitana en la gestión de los recursos naturales del espacio rural, en específico, el caso de la gestión del agua para la ZML.

La gestión comunitaria del agua

No hay un consenso claro en cuanto a la tipología de las formas de gestión del agua. Para facilitar el análisis del caso de investigación propuesto, se retoma la clasificación que hace Díaz (2017) en torno a cuatro formas de gestión del agua: la pública, la privada, la comunitaria y la cogestión. Por su parte, Hatch-Kuri (2017) advierte la necesidad de identificar y reconocer la coexistencia de dife- 
rentes mecanismos de apropiación, acceso y distribución del agua a lo largo del país; también sostiene que existen dos sistemas paralelos de gestión y de distribución del agua subterránea: la que realiza el Estado (a través de instituciones como la Comisión Nacional del Agua [CONAGUA] y los sistemas operadores estatales y municipales) y la que realizan los sistemas comunitarios del agua.

En esta línea de gestión comunitaria del agua, Ostrom (2011 [1990]) aporta una importante reflexión en torno a la administración de los bienes comunes, explicada a través de la capacidad de autogestión que de sus recursos tienen los actores. La autogestión es una alternativa a las gestiones pública y de mercado que posiciona en un punto relevante a las comunidades que anteriormente habían sido descalificadas por los teóricos del Estado y del mercado debido a una supuesta incapacidad de gestión responsable. Para Ostrom, los tipos de bienes y los derechos de propiedad dan la pauta para determinar el modelo de gestión, de ahí que el agua como bien común - de baja exclusión y alta rivalidadrequiere un acercamiento a las distintas formas de apropiación, provisión y propiedad que de ella se hacen de acuerdo con cada contexto social particular (Merino, 2014; Ostrom (2011 [1990]).

En este sentido, una categoría de amplia relevancia dentro del análisis desarrollado por Ostrom es la capacidad institucional, entendida como la capacidad de generar reglas de decisión y de gestión de los propios actores sobre los recursos de los cuales dependen (Aguilera, 2009). El estudio de la gobernanza económica de los bienes comunes, como el caso del agua, requiere un acercamiento detallado a los actores como un componente esencial para comprender la gestión de los recursos; actores que deberán ser vistos como individuos con capacidad de cooperar en vez de competir y que permiten el desarrollo de lo que se conoce como la acción colectiva. De esto depende el fomento de una gobernanza en la que el uso y el manejo de los recursos se dan bajo una lógica de usufructo transitorio, sin agotarlos ni destruirlos. No obstante, es necesario mencionar, como señalan Blomquist y Ostrom (1992), que el conflicto es inherente en la gestión comunitaria de los recursos naturales, lo cual quiere decir que hay espacio para las dificultades y los errores, pero tales experiencias se pueden sistematizar para discurrir en posibles soluciones (Aguilera, 2009).

Bajo esta línea de argumentación, la gestión comunitaria del agua en las comunidades rurales ha tenido un desarrollo particular en cada una de ellas desde el reparto agrario para el caso mexicano. En cada comunidad rural, la figura del comité del agua es la autoridad en materia de gestión hídrica, desde donde emanan las reglas del juego bajo las cuales se van a regir los actores para el uso y el manejo del líquido. Los comités basan su labor en el conocimiento y uso tradicional del agua en la pequeña escala que supone su territorio. Con apoyos financieros, ya sean federales, estatales o municipales, pero también con la recaudación de cuotas de los habitantes, han sostenido la construcción de los sistemas de operación y distribución del recurso hídrico.

El comité del agua suele estar conformado por un grupo de habitantes de la comunidad que se elige en asamblea y cuyas funciones son la extracción, la potabilización y la distribución de agua potable a las viviendas y comercios instalados en la delimitación territorial. De la mano de las tareas asignadas a 
los miembros del comité, se teje una importante red de relaciones de poder entre ellos y los miembros de la comunidad. Esta gestión rural del agua para uso doméstico convive con la concesión de pozos agrícolas en las tierras de cultivo que conforman el territorio de cada comunidad, normalmente gestionado por las autoridades ejidales.

El modelo de gestión comunitaria del agua se caracteriza por tener "sus propias reglas, prácticas, arreglos, sanciones, restricciones, valores y organización, todo lo cual responde a formas locales que han perdurado a través de adaptaciones a otros modos de gestión del agua, por ejemplo, el municipal" (Díaz, 2017, p. 302). En este sentido, es común que cada comité haya determinado una serie de parámetros en torno a la administración del recurso que puede modificarse cuando el contexto así lo requiera (Escobar, 2017). Estas características hacen que la gestión comunitaria del agua no sea fácilmente tipificada a lo largo del país, porque las prácticas sociales y los conocimientos tradicionales tienen una importante influencia en la forma en que se gestiona el agua. Puede decirse que existen tantas formas de gestión comunitaria del agua como comunidades existan, tal como señalan Blomquist y Ostrom (1992).

Las representaciones sociales del agua en las localidades bajo estudio

La comprensión que los habitantes tienen del agua como un recurso o elemento natural tiende a modificarse. Se entiende el agua como un servicio público que los acerca al progreso y a los beneficios de la urbanización de la ciudad-, como un bien económico con un valor de uso y un valor de cambio que implica el acaparamiento por parte de algunos para el beneficio propio $y$, finalmente, como un elemento indispensable para la vida imposible de mercantilizar (Arrojo, 2006).

Entre las distintas generaciones de habitantes de las comunidades se han construido diferentes percepciones del agua: para los adultos mayores, por ejemplo, el agua ha estado siempre presente en el entorno, corriendo en los ríos y brotando del suelo en forma de veneros. Las nuevas generaciones se han alejado poco a poco de esta experiencia con la naturaleza, en especial los más jóvenes, porque el agua ha estado presente siempre en sus casas a través de una toma. De ahí que el agua sea un servicio público más que un elemento natural. Entre tanto, la escasez y la competencia entre los distintos usos del agua hacen emerger una comprensión del recurso hídrico como un recurso económico que se vuelve necesario adquirir a un precio competitivo para las actividades productivas. De no ser así, la competencia dentro del mercado se vuelve avasallante (Arrojo, 2006; Barkin, 2006; Tagle, Caldera y Fuente, 2019).

Con el agua entubada en casa, las mujeres -encargadas del abastecimiento y de la administración del agua - tienen mayor control sobre sus actividades diarias y a su vez tienen la oportunidad de salir a trabajar en el mercado laboral urbano. La situación de escasez a la que se enfrentan en la administración del hogar ha motivado una profunda cultura del agua orientada a las prácticas de reúso. 


\section{Descripción del área de estudio}

León es la ciudad más importante del estado de Guanajuato. En 2015 se contabilizaron 1578626 habitantes (Instituto Nacional de Estadística y Geografía [INEGI]) (aproximadamente 20\% del total del estado) y una extensión de 1283.88 kilómetros cuadrados $\left(\mathrm{km}^{2}\right)$ (de los cuales $16.89 \%$ pertenece al área urbana) (Tagle, 2016). Colinda al norte con el municipio de San Felipe; al este, con Silao y Guanajuato; al sur, con Romita, San Francisco del Rincón y Purísima del Rincón; y al oeste, con los municipios de Lagos de Moreno y Unión de San Antonio en Jalisco.

Como antecedente, en 1990 León pasó a ser una de las 21 zonas metropolitanas del país junto con San Francisco del Rincón, aunque cabe reconocer que "la denominación de zona metropolitana se adopta por consideración al tamaño poblacional de León y por su influencia en el resto de las localidades del municipio, no por razones de conurbación o de influencia regional a otras ciudades" (Mata, 2009, p. 52). En 2008, el Instituto de Planeación del Estado de Guanajuato (IPLANEG) constituyó la zona conurbada y metropolitana de León con los municipios de Silao, San Francisco del Rincón y Purísima del Rincón, municipios que, de acuerdo con Suárez, Martínez y García (2015), son periféricos y contiguos con características periurbanas que sostienen una importante interrelación con la ciudad central, que es León. Esta zona metropolitana cubre un área de $3087 \mathrm{~km}^{2}$. No obstante, la Secretaría de Desarrollo Social (SEDESOL) y el Consejo Nacional de Población (CONAPO) consideran que León y Silao conforman una zona metropolitana y Purísima del Rincón y San Francisco del Rincón conforman otra. Por la cantidad de población, la zona metropolitana de León ocupa la sexta posición de entre las 55 áreas metropolitanas reconocidas por el INEGI (Suárez, Martínez y García, 2015) bajo la misma categoría que manejan SEDESOL y CONAPO.

Para el desarrollo del presente trabajo, se adopta la delimitación de zona metropolitana que propone el IPLANEG y considera los municipios de León, San Francisco del Rincón, Silao y Purísima del Rincón (véase figura 1). En tal zona metropolitana, la ciudad de León cumple la función de ciudad central, ya que domina las interacciones comerciales, sociales y culturales con el resto de los municipios (Martínez y Suárez, 2015).

La ZML es la más importante en las dimensiones poblacional y económica del estado de Guanajuato. Durante el año 2011, "el producto interno bruto de la ZML era de 336114 millones de pesos, con un producto interno per cápita de 185514 pesos, y con una inversión de 100480 millones de pesos" (Martínez y Suárez, 2015, p. 243). En León, 90\% de la población vive en localidades urbanas, en Purísima del Rincón lo hace 63\%, en San Francisco del Rincón 60\% y en Silao 59.7\% (Suárez, Martínez y García, 2015).

Resulta evidente que los cambios en la actividad económica de la ZML han generado también un crecimiento rápido y a su vez modificaciones en el uso del suelo. El suelo agrícola ha dado paso a la instalación de parques industriales 
Figura 1. Zona metropolitana de León (ZML)

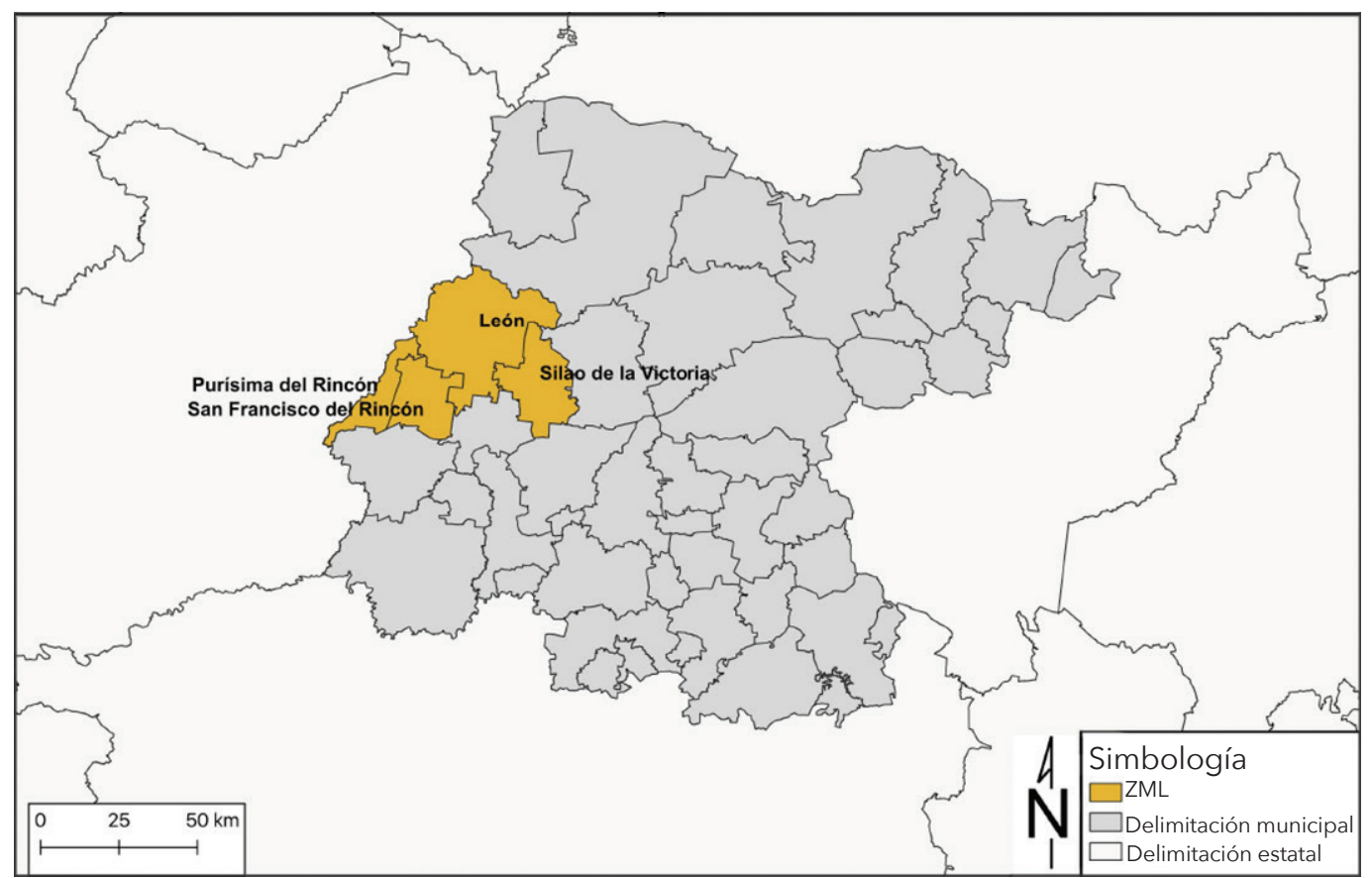

Fuente: elaboración propia.

y otras obras de infraestructura, como el Puerto Interior. ${ }^{3}$ Esto sucede aun a pesar de la existencia de tierras de propiedad ejidal: "la tenencia de la tierra ha ido pasando de ejidatarios a empresas inmobiliarias, o incluso al gobierno, quien ha decidido usar estas tierras para el establecimiento de parques industriales o de alguna empresa transnacional” (Martínez y Suárez, 2015, p. 252). No obstante, aún existen grupos ejidales que se resisten a la venta de sus tierras, lo que genera un territorio fragmentado.

Descripción de las comunidades de estudio:

La Laborcita, Ladrilleras del Refugio y Loza de los Padres

En la actualidad, las comunidades La Laborcita, Ladrilleras del Refugio y Loza de los Padres se encuentran en un proceso de transición que tiende a la conurbación con la ciudad de León desde la particularidad de cada territorio. Las comunidades se encuentran dentro del área que concentra la expansión urbana de León para encontrarse con la expansión urbana del municipio de Silao. En este espacio geográfico se aglutinan importantes clústeres industriales automotrices y el clúster Puerto Interior, impulsado por el gobierno estatal, las ensambladoras de autos Volkswagen y General Motors, el Aeropuerto Internacional del

3 "Una de las obras más importantes del gobierno estatal que está en proceso, y comprenderá: una aduana interior para efectuar importaciones y exportaciones, una zona de servicios, una terminal intermodal que facilite la conexión entre ferrocarril y autotransporte para el transporte de mercancías, y un parque industrial" (Martínez y Suárez, 2015, p. 251). 
Bajío, entre otras actividades económicas orientadas al sector de los servicios (Álvarez, 2016; Rodríguez y Caldera, 2013; Tagle, Caldera y Rodríguez, 2017).

Las tres comunidades se ubican al poniente del municipio, donde están interconectadas por el recién construido Eje Metropolitano León-Silao, la carretera México 45 y el bulevar La Luz (véase figura 2). Estas tres vialidades permiten la conexión de la ciudad de León con el resto del corredor industrial del Bajío guanajuatense y con otras ciudades vecinas, como Querétaro, San Luis Potosí, Guadalajara y Ciudad de México. A lo largo de estas vialidades se han desarrollado la vivienda de interés social y la vivienda residencial, así como complejos industriales cuya localización permite conectar, a través de las vías de comunicación, con distintos centros industriales y comerciales entre las ciudades y metrópolis ya mencionadas.

Figura 2. Comunidades de estudio dentro de la zona metropolitana de León

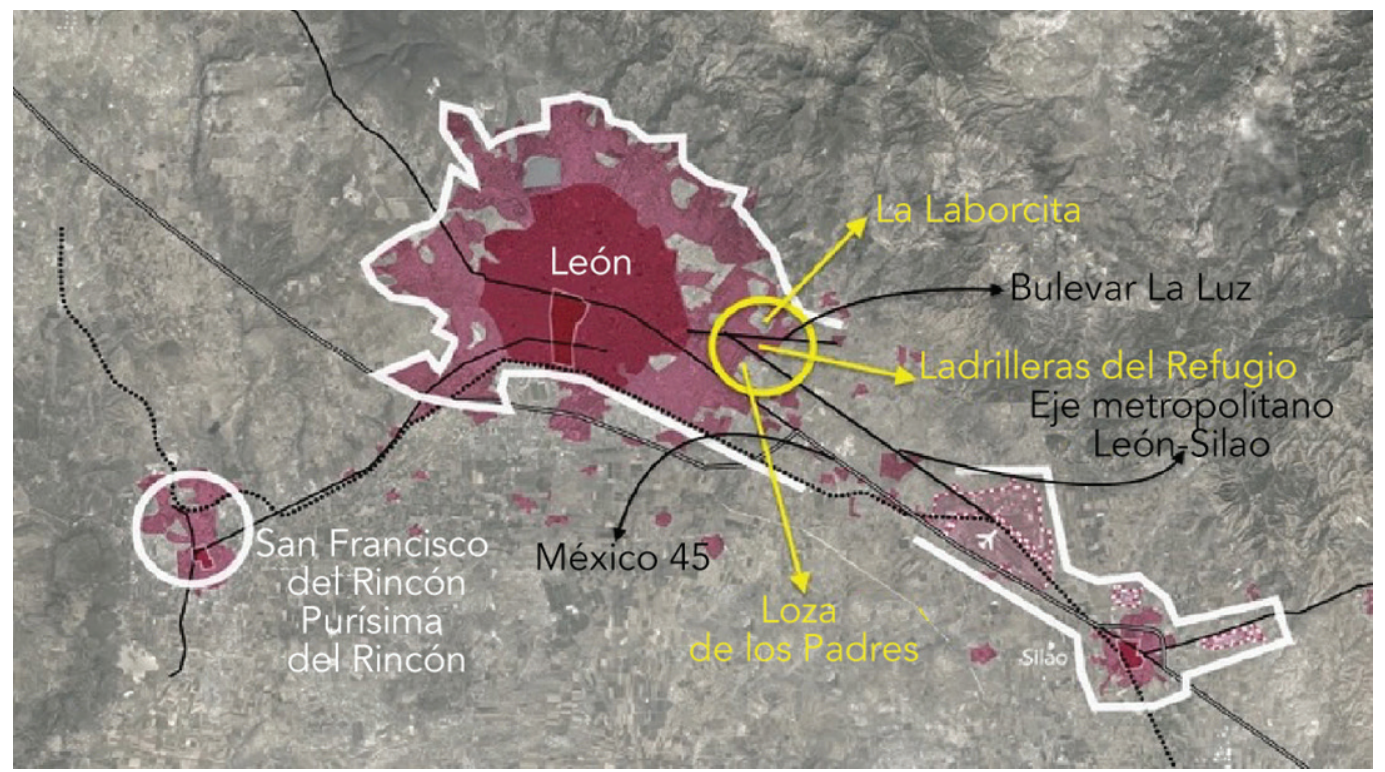

Fuente: modificada a partir de Les Ateliers (2013). Zona metropolitana de León, paisaje y suelo para compartir.

La Laborcita y Loza de los Padres son comunidades que a través de la historia han sostenido su crecimiento a partir de la actividad agrícola desarrollada en el ejido; por su parte, Ladrilleras del Refugio es una comunidad rural de reciente conformación que se dedica a la elaboración de tabique. Loza de los Padres es la comunidad con mayor población, seguida de Ladrilleras del Refugio y La Laborcita (véase tabla 1). Destaca el decrecimiento de la población en La Laborcita durante la década de 2000, que se recupera hacia el año 2010. En Ladrilleras del Refugio es relevante el incremento de la población, considerando que el asentamiento se estableció apenas a finales de la década de 1980. 
Tabla 1. Crecimiento poblacional en las comunidades, 1990-2010

\begin{tabular}{|c|c|c|c|}
\hline Localidad & 1990 & 2000 & 2010 \\
\hline La Laborcita & 1119 & 958 & 1567 \\
\hline Loza de los Padres & 1946 & 2290 & 2875 \\
\hline Ladrilleras del Refugio & $\begin{array}{c}\text { *Aún no constituida } \\
\text { como comunidad }\end{array}$ & 1016 & 1642 \\
\hline
\end{tabular}

Fuente: elaboración propia con datos de INEGI. Censos 1990, 2000 y 2010.

Loza de los Padres es también la comunidad que cuenta con mayor cantidad de servicios. Puede decirse que cuenta con más cualidades de urbanización frente a La Laborcita y Ladrilleras del Refugio. Es común que los habitantes de estas dos comunidades recurran a Loza de los Padres en busca de atención médica, abasto de algún alimento o bien la prestación de algún servicio especializado, como las bandas de música para eventos sociales.

\section{Aspectos metodológicos}

Partiendo del objetivo de la investigación, se utilizó un enfoque cualitativo que permitió un acercamiento a los significados y a las prácticas que han dado lugar a determinadas condiciones para que los actores involucrados desarrollen argumentos a favor o en contra de la municipalización de las comunidades periurbanas ya descritas y que están delimitadas dentro de la ZML (Cadena, Cruz y Maass, 2011; Cirelli, 2004; Escobar, 2017; Fontecilla, 2015; Galindo y Palerm, 2016; Jalomo y Martí, 2016).

Dada la problemática planteada en relación con la comprensión de las percepciones sociales (Berger y Luckmann, 2003) del proceso de municipalización del agua, el enfoque cualitativo permite un acercamiento a los discursos e intereses (Maceira, 2011) de los habitantes de las comunidades ante la iniciativa de la autoridad para municipalizar el servicio de agua potable. Este enfoque permite comprender y visibilizar las motivaciones de los actores para aceptar o rechazar la incorporación.

Las técnicas elegidas para la recolección de datos fueron la entrevista a profundidad y la observación no participante (Geertz, 2003). El acercamiento a los informantes se realizó mediante la técnica de bola de nieve hasta que la información obtenida en las entrevistas fue suficiente para llegar al punto de saturación, ${ }^{4}$ que permitió un total de 34 entrevistas a profundidad desarrolladas con una guía semiestructurada. La selección de los informantes se determinó a partir de un proceso de análisis a través del cual se identificaron los principales actores involucrados en la problemática a estudiar. Durante la aplicación de las entrevistas fue común que otras personas se integraran a la conversación, ofreciendo mayor riqueza de perspectivas y opiniones en los temas propuestos. Por

4 Saturación de categorías: cuando los datos se vuelven repetitivos o redundantes y los nuevos análisis confirman lo que se ha fundamentado (Hernández, 2019, p. 459). 
otro lado, la observación no participante se realizó en varios recorridos en cada comunidad durante el reconocimiento del territorio y el levantamiento de las entrevistas. El proceso de recolección se realizó durante varias visitas al campo en el periodo de marzo a mayo de 2018.

Las unidades de análisis para el estudio fueron tres comunidades que permitieran una triangulación de datos y fuentes. En este sentido, se eligieron las siguientes comunidades rurales de acuerdo con su condición respecto de la gestión del agua: La Laborcita, como comunidad que mantiene una gestión del comité rural del agua porque años atrás rechazó su incorporación al Sistema de Agua Potable y Alcantarillado de León (SAPAL); Ladrilleras del Refugio, que inició su proceso de incorporación al SAPAL en 2017 y fue finalizado al comienzo de 2018; y Loza de los Padres, comunidad en la que ahora se vive el conflicto y los desencuentros por las iniciativas del proceso de incorporación al sistema municipal desde el año 2016.

Las entrevistas fueron dirigidas a 1) amas de casa, 2) miembros del comité del agua y delegados de la comunidad, 3) ladrilleros, 4) agricultores y 5) funcionarios involucrados en los procesos de incorporación. Esta selección de informantes debía reflejar las prácticas de los distintos usos que se le da al agua -doméstico, agrícola e industrial-, así como las distintas representaciones sociales sobre el recurso - bien económico, recurso natural, derecho humano y servicio público- que fueron develándose en los discursos de los informantes.

Bajo los anteriores supuestos, se buscó confrontar las dos lógicas de gestión planteadas, la urbana y la rural, para manifestar el contexto y los componentes que han motivado la incorporación o la resistencia a la gestión comunitaria del agua ante el proceso de municipalización por parte del organismo operador.

\section{Desarrollo}

El proceso institucional

para la municipalización del agua comunitaria en León

Para el caso particular del estado de Guanajuato, la Ley de Aguas para el Estado de Guanajuato, vigente desde el año 2000, concede a los municipios la atribución del servicio de agua potable y alcantarillado tanto a las zonas urbanas como a las rurales, con sustento en el artículo 115 constitucional. En el caso del municipio de León, coexistían un reglamento del Sistema de Agua Potable y Alcantarillado de León, modificado en 1996 y después en 1997, y uno propio para los sistemas rurales de agua y saneamiento en las comunidades rurales del municipio de León, expedido en 1994 y vigente hasta su abrogación en 2009, sustituido por el nuevo Reglamento de los Servicios de Agua Potable, Alcantarillado y Saneamiento de León.

Los reglamentos del sistema de agua potable de los años 1996 y 1997 no hacían una referencia directa a la administración del agua en las comunidades rurales; sin embargo, se hace referencia en el de 1996 a que el Sistema de Agua Potable y Alcantarillado de León (SAPAL) puede otorgar asistencia técnica a los 
sistemas rurales que así lo requieran. En el de 1997 no se hace referencia a las comunidades rurales.

En el reglamento de los sistemas rurales de agua potable se establecía, entre otras cosas, que estos sistemas podían constituirse en cada comunidad rural de manera descentralizada del municipio, con una personalidad jurídica y un patrimonio propios. En el artículo tercero de ese reglamento se definían los sistemas rurales de agua potable de la siguiente manera (Municipio de León, 1994):

Se entiende por Sistema Rural de Agua Potable y Saneamiento, el conjunto de obras, equipos e instalaciones que permiten la prestación de los servicios de agua potable, alcantarillado y saneamiento para un núcleo de población rural en el Municipio y en donde se tiene en común, la fuente de abastecimiento y/o la descarga de aguas residuales y en su caso el tratamiento de aguas residuales. (p. 3)

A partir de este reglamento se establece la posibilidad de incorporar el sistema rural a la administración del SAPAL bajo la demanda de utilidad pública. En el reglamento se establece también que los sistemas rurales de agua potable y saneamiento se regirán por una asamblea general, mediante la cual se constituirá un comité de administración y vigilancia con apoyo de la Dirección de Desarrollo Rural del municipio. Entre las funciones principales de los comités están las de distribuir y sanear el agua potable para el uso doméstico en las comunidades rurales a aquellos propietarios de predios que soliciten el servicio mediante un contrato y una cuota mensual. Así mismo, se considera que el servicio de agua potable puede destinarse al uso animal, al regadío de huertos familiares y al uso recreativo. Se asigna al comité la labor de distribuir el agua potable en los horarios pertinentes, de acuerdo con las posibilidades de cada sistema rural; del mismo modo, el comité tiene la capacidad de suspender o de restringir el servicio, con previo aviso a los usuarios, por causas relacionadas con la escasez del recurso o debido a la reparación de la infraestructura.

Como se mencionó antes, el reglamento de 1994 fue abrogado en 2009 una vez que fue aceptado el Reglamento de los Servicios de Agua Potable, Alcantarillado y Saneamiento de León. En el nuevo reglamento se establece la creación del SAPAL Rural, entidad encargada de abastecer el servicio de agua potable y alcantarillado a las comunidades rurales del municipio, con lo que desaparecen las funciones y las responsabilidades de los sistemas rurales de agua.

Después el Reglamento de los Servicios de Agua Potable, Alcantarillado y Saneamiento de León se modificó nuevamente en 2010 y en 2017 para sentar bases cada vez más claras sobre el objetivo y las atribuciones del SAPAL Rural.

Se creó ese organismo con el objetivo de dar el servicio de agua potable, alcantarillado y tratamiento de aguas residuales a las comunidades rurales del municipio de León para "brindar mejores condiciones de vida para la gente del campo" (SAPAL, 2012, p. 165) y "prestar los servicios con la misma calidad que en las áreas urbanas" (SAPAL, 2012, p. 169). Pero también se trata de un proyecto a mediano y largo plazos que implica que el municipio de León integre la administración total del agua en el municipio y también en la zona metropolitana (SAPAL, 2012): 
En el largo plazo, es posible que SAPAL Rural se fusione con SAPAL para integrar un solo organismo que atienda a todo el municipio de León, en particular con la eclosión de la zona metropolitana de León, que abarca varios municipios. Por ello, resulta deseable que un solo organismo intermunicipal aproveche las economías de escala en la prestación de los servicios públicos de agua potable y saneamiento. (p. 169)

En el cumplimiento de estos objetivos, el SAPAL Rural comenzó por hacerse responsable de las cuentas de las 17 comunidades rurales que ya formaban parte de la cartera del SAPAL. En el año 2018, ya habían sido incorporadas un total de 22 comunidades $^{5}$ en un contexto de resistencia de algunas comunidades y de solicitud de incorporación por voluntad propia de otras. Con esas 22 comunidades incorporadas se atienden a más de veinte mil habitantes a través de 3942 tomas domiciliarias (SAPAL, 2018).

El proyecto de incorporación de las comunidades rurales ha involucrado el esfuerzo de otras instituciones municipales, en especial de la Dirección de Desarrollo Rural. Esa Dirección tiene la tarea de acompañar el trabajo social para abrir paso a las tareas técnicas del SAPAL Rural una vez que la infraestructura hidráulica existente en las comunidades haya sido cedida por las autoridades locales. Es necesario destacar que el SAPAL pone el énfasis en la necesidad de tener un respaldo total de las autoridades municipales para cumplir las metas de la incorporación, lo que justifica incluso el uso de la fuerza pública.

Tres casos de municipalización del agua comunitaria en León: aceptación, rechazo e indefinición

El análisis a partir de ahora se centra en las comunidades de estudio seleccionadas en el municipio de León, puesto que ahí se concentra la ciudad central de la zona metropolitana y la ciudad que ha absorbido más suelo rural para sostener su crecimiento. Paralelamente al desarrollo urbano de León, la vida en el entorno rural se desarrolló de acuerdo con las diferencias y características que han conformado hasta la actualidad las comunidades rurales que han sido consideradas para el estudio: La Laborcita, Ladrilleras del Refugio y Loza de los Padres. En este panorama, las comunidades que interesan al estudio se han enfrentado al proceso de incorporación desde diferentes situaciones en las que se ha presentado el conflicto.

Ladrilleras del Refugio inició su proceso de incorporación durante el año 2017 y se formalizó a inicios de 2018 con la firma de contratos del servicio de agua potable y la instalación de medidores en las viviendas. La Laborcita negó la incorporación en 2016 a partir del consenso de sus habitantes a través de la representación del comité del agua y los delegados. En Loza de los Padres se planteó en 2016 una estrategia de intervención y de comunicación social con

5 El Nacimiento, El Ramillete, Estancia de Vaqueros, La Correa, La Mora, La Reserva, La Sandía (El Tope), La Venta, Ladrilleras del Refugio, Lagunillas, Los Arcos, Los Tepetates, Ojo de Agua de los Reyes, Piedra Blanca, Puerta de San Germán, Puerta del Cerro, Rancho de los Naranjos, Rancho San José del Consuelo, San Antonio del Monte (Malagana), San José del Resplandor (El Capricho), San Judas y Santa Rosa Plan de Ayala (SAPAL, 2018). 
una duración de tres meses para informar a los habitantes sobre los beneficios de la incorporación: la comunidad se dividió entre quienes estaban de acuerdo y quienes no estaban de acuerdo, aunque, finalmente, la negativa y la hostilidad de grupos de habitantes hacia cualquier obra relacionada con el SAPAL impidió el desarrollo del proyecto.

Las tres comunidades de estudio se abastecen de agua subterránea para el uso doméstico a través de un pozo que es administrado por un comité. Los comités están conformados por miembros de cada comunidad que se eligen a través de una asamblea, en un proceso que está a cargo de la Dirección de Desarrollo Rural del Municipio de León. Estos comités se rigen por acuerdos establecidos en asamblea. La gente suele referirse a los comités como "los que echan el agua", "el que cobra el agua", "los encargados del pozo".

Las funciones de cada comité del agua, heredadas del reglamento de los sistemas rurales del agua del año 1994, son las de administrar y operar el sistema de agua de su comunidad correspondiente a través de asambleas, así como la de dar mantenimiento a la infraestructura para poder llevar a cabo sus funciones y clorar el agua extraída garantizando que la población tenga acceso a agua potable. Cabe destacar que el agua de los pozos que administran los comités es exclusivamente para uso doméstico. Las actividades económicas, como la elaboración del tabique y la agricultura, tienen otra fuente de abastecimiento, ya sea un pozo que es administrado por los tabiqueros o los ejidatarios, o bien pozos agrícolas, agua de presas, cuerpos de agua y del temporal de lluvia para la actividad agrícola.

Las decisiones sobre la administración del agua en las comunidades rurales dependen del comité, de un grupo de personas o a veces de una sola persona, que, basados en costumbres, desempeñan sus funciones. La figura del comité del agua no es imparcial, sino que sus múltiples roles sociales en la comunidad tienen una influencia importante en la ejecución de sus tareas, lo cual se evidencia en la tolerancia a la cartera vencida y los cortes de suministro arbitrarios de los que se queja la población. Se suma que los comités de agua están en una posición de poder en la comunidad y esta posición ha sido aprovechada por grupos políticos que ejercen presión sobre los delegados de la comunidad y otras figuras de liderazgo. Lo anterior es un componente suficiente en las comunidades para determinar su incorporación al sistema municipal de agua potable.

Para llevar a cabo la tarea del abastecimiento doméstico, se cobra una cuota mensual determinada por cada comité. Esta cuota no suele cubrir los gastos de mantenimiento o de compostura de la infraestructura, por lo que, cuando ocurre algún inconveniente de este tipo, el comité solicita una cuota extraordinaria a la población. Los comités deberían renovarse cada tres años, con el cambio de gobierno local, pero en algunos casos no sucede.

Una de las problemáticas que comparten los sistemas rurales es la relacionada con el manejo y la rendición de cuentas, lo que dificulta conocer con exactitud el desempeño de cada uno de los sistemas rurales. En otro sentido, la falta de trasparencia en el manejo de los recursos que ingresan al comité es el principal motivo de desconfianza de los habitantes. 
La experiencia de las comunidades periurbanas de la ZML ante los procesos de municipalización La Laborcita

En esta comunidad el agua se recibe todos los días durante tres o cuatro horas, ya sea por la mañana o por la tarde, pues primero se bombea agua a la parte norte de la comunidad y después a la parte sur. Se paga una cuota mensual de ochenta pesos por familia, sin importar la cantidad de agua que se consuma.

Las entrevistas realizadas mostraron que es común el incumplimiento del pago de las cuotas al comité, lo que dificulta el trabajo de operación y de mantenimiento. Esta situación, además, genera inconformidad en quienes sí mantienen el pago de sus cuotas al corriente. El comité del agua está representado por una persona encargada del bombeo de ésta desde el pozo, para que sea distribuida a toda la comunidad, y un grupo de personas que se encarga de cobrar las cuotas mensuales, pero que poco figura en el discurso de la población sobre el comité del agua.

Se observó en la población una alta tolerancia al incumplimiento de las funciones de los miembros del comité, puesto que hay una relación de confianza por ser habitantes de la comunidad. Desde la perspectiva de los adultos mayores de la comunidad, quienes se han enfrentado durante años a distintas etapas respecto a la gestión del agua -como fue el acarreo de agua directamente de las fuentes de abastecimiento, así como la construcción de los primeros pozos para el bombeo y la construcción de infraestructura para llevar de manera directa el recurso a las viviendas-, el comité actual cumple con menos funciones que las que realizaban los antiguos comités.

La comunidad rechazó el proyecto de incorporación de las comunidades rurales a la administración del SAPAL Rural. Estallaron fricciones con los miembros del comité, a quienes acusaban de vender el patrimonio de la comunidad sin consultarles. En especial se observa una gran desconfianza en el organismo operador municipal, y en las autoridades en general, con respecto a la forma en que se llevan a cabo los proyectos de interés público, pues a menudo se ponen en marcha a través de la imposición y con engaños. El caso particular de la administración del agua, además, se ve como una intromisión a la autonomía de la comunidad y se percibe como el arrebato del patrimonio y de los recursos propios. Hay que añadir que entre los habitantes se comparte la inquietud de la instalación de medidores para el control del consumo del agua en las viviendas, puesto que se rumoraba que estos aparatos "miden el aire" que se filtra por los tubos y lo cuentan como consumo de agua, lo que resulta en una cuota más alta que no corresponde con el agua realmente consumida.

La actividad pecuaria que se lleva a cabo en la comunidad suele usar el agua proveniente de las tomas de las viviendas. Esa agua se usa para completar la alimentación de su ganado, debido a que hay cada vez menos cuerpos de agua disponibles a distancia razonable para llevarlo a beber, como consecuencia de la urbanización del entorno sobre el suelo rural. En este sentido, la oposición de ese grupo de actores a la incorporación es determinante porque aumenta de manera significativa sus costos de producción de ganado. Finalmente, la pobla- 
ción, en consenso, se negó a los proyectos de incorporación con los argumentos anteriores y no cedió la infraestructura al organismo municipal.

\section{Loza de los Padres}

En esta comunidad el comité que administra el agua es el mismo desde hace casi diez años. Ese comité no ha dejado el puesto debido a la falta de participación de los habitantes de la comunidad para tomar la responsabilidad del cargo. Está conformado por el presidente, el secretario, el tesorero y dos vocales. Una de las peculiaridades de la población de Loza de los Padres es que hay un número considerable de la población masculina que trabaja o trabajó en el SAPAL. Éste es el caso de al menos la mitad de los miembros del comité.

La comunidad es cada vez más grande: el número de viviendas a las que hay que llevar el agua es también mayor y la presión parece no ser suficiente para las partes más altas y alejadas de la comunidad, lo cual genera un acceso desigual al agua. Las viviendas de la comunidad reciben agua cada tercer día durante dos o tres horas por las mañanas, como una medida que se toma para evitar el alto consumo de energía eléctrica para el bombeo del pozo. Se paga una cuota de 90 pesos mensuales por familia. La cuota fija establecida por el comité del agua cubre el gasto del mes sin importar la cantidad que se consuma; sin embargo, cuando hay fallas en la infraestructura de la fuente de abastecimiento, se piden cuotas extraordinarias a los habitantes de la comunidad. Además, los miembros del comité no reciben entrenamiento formal para la operación y el mantenimiento de la infraestructura. Sus conocimientos son empíricos.

También se hacen cuestionamientos sobre el manejo de las cuotas en el interior del comité. La gente relata un mal manejo de los fondos, así como poca trasparencia en las cuentas. A los miembros del comité se les acusa constantemente de obtener beneficios y ganancias adicionales por llevar el cargo. Por otro lado, los miembros del comité defienden su labor, argumentando que, con la cartera vencida a cuestas, no es posible dar un mantenimiento adecuado a la infraestructura y llevar al corriente los pagos de la energía que se usa en el bombeo. Ésta ha sido una de las situaciones que ha hecho a los miembros del comité considerar la opción de ceder la responsabilidad a SAPAL, pero temen las represalias de los habitantes.

En referencia al uso doméstico del agua, la incorporación toma otros carices, ya que el acceso al agua es limitado a ciertos días y horas de la semana, lo que condiciona las actividades domésticas. Cuando se contrasta la operación del sistema operador municipal con la calidad del servicio que la comunidad obtiene mediante el sistema rural, la incorporación se convierte en una opción que podría mejorar la calidad de vida. No obstante, el aumento de la cuota ofrece mucha resistencia de la población, que no está dispuesta a pagar un servicio más caro.

En Loza de los Padres no hubo acuerdo entre los habitantes de la población para que la decisión de incorporarse fuese unánime. Además, se observaron rasgos de movilización política detrás de los grupos manifestantes por parte del 
partido político opositor al gobierno en turno. De ahí que el conflicto se viviera de manera intensa durante la etapa de socialización del proyecto. Incluso hubo declaraciones a los medios de comunicación en las que se hablaba de amenazas de bloqueos, plantones y levantamientos violentos. En cualquier caso, el peso de la responsabilidad cae sobre los delegados y los miembros del comité del agua, quienes a su vez temen las represalias de los demás miembros de la comunidad con quienes conviven todos los días.

En nuestros días la comunidad continúa recibiendo el servicio de agua potable a través del sistema rural de agua de manera insuficiente para una población de más de cuatro mil habitantes. El sistema rural de Loza de los Padres está rebasado para llevar a cabo sus funciones a cabalidad.

\section{Ladrilleras del Refugio}

Esta comunidad ha sido incorporada al organismo municipal, pero antes de ello su fuente de abastecimiento era administrada por un comité designado por sus habitantes. Este caso es muy particular, puesto que la comunidad en sí se sabía propietaria de dos pozos: uno destinado al consumo doméstico y otro destinado a la fabricación del tabique. Cada uno de esos pozos era administrado por un comité encabezado por un "administrador" y un grupo de personas que “cobraban el agua". El comité del pozo de uso doméstico era designado por la población a través del apoyo de la Dirección de Desarrollo Rural del municipio; y por su parte, el comité del pozo de las ladrilleras era designado en un proceso similar por los "patrones” de éstas.

Ambos pozos tuvieron dificultades en el mismo periodo: el pozo para el uso doméstico se secó y dejó a la población sin agua durante al menos dos años, puesto que el costo de la reparación y las acciones necesarias para volver a perforar otro pozo superaban por mucho la capacidad de pago del comité, que dependía de las cuotas cobradas al mes. Durante este periodo, comprar agua de pipa y recolectar el agua de lluvia fue la solución que la población encontró para proveerse del recurso.

Por su parte, el pozo destinado a la fabricación del tabique fue clausurado por la CONAGUA, debido a inconsistencias en el título de concesión que debía estar a cargo del comité que le correspondía. Desde ese momento, la compra de agua de pipa, o la compra directa a pozos agrícolas, ha sido la solución que los ladrilleros han encontrado a su problema de acceso al agua. Sin embargo, esto ha incrementado notablemente sus costos de producción, lo cual ha puesto en riesgo la sostenibilidad del negocio debido a ganancias cada vez más bajas.

El pozo para uso doméstico bombeaba agua a las viviendas cada tercer día por las mañanas, por una cuota mensual de cincuenta pesos. No obstante, durante los dos años de fallas constantes en el suministro de agua, la población se vio en la necesidad de gastar más en la compra de agua de pipa, así como de agua embotellada para el consumo humano.

La población desconfiaba del manejo de las cuotas que ingresaban a las arcas de ambos comités porque, a pesar de que las cuotas se mantenían al día, no mejoraba el servicio. Se sospecha y se conversa entre los habitantes que los 


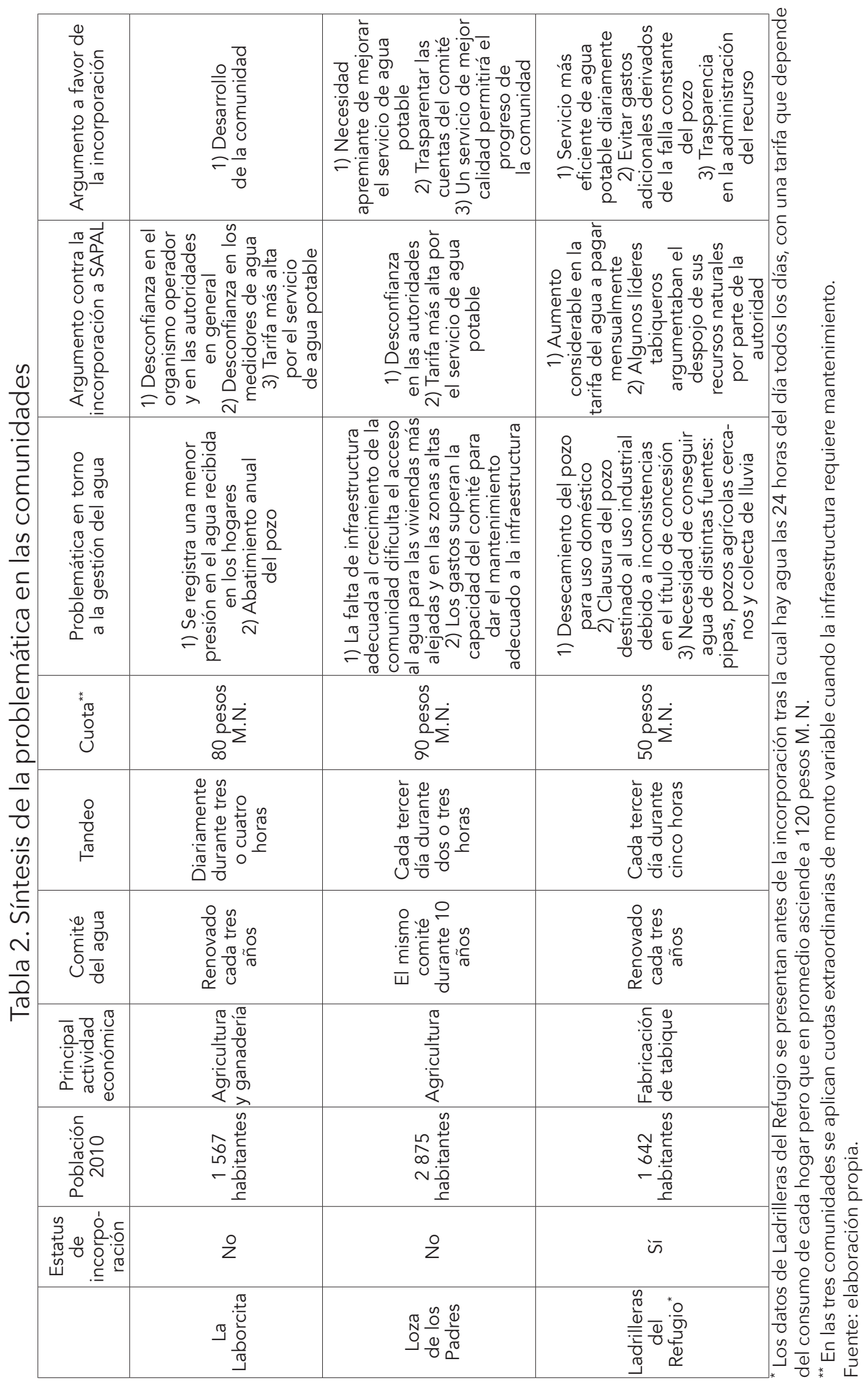


miembros del comité usaban el dinero para beneficio propio, o bien para hacer negocios personales con el agua que es de todos y con la infraestructura de los pozos, de los cuales hacían uso como propietarios legítimos. Por su parte, los miembros del comité argumentan que el tandeo de agua se debe a la necesidad de dar uso racional al agua y garantizar el ahorro en el gasto de energía eléctrica.

El proceso de incorporación en esta comunidad también pasó por un momento de conflicto entre quienes alegaban la propiedad de los pozos y del recurso hídrico -es decir, los miembros del comité del agua- y la población que exigía un servicio de agua regular en sus viviendas y la población que no estaba dispuesta a pagar una tarifa más alta que la que pagaban al comité.

En asamblea, la población aceptó por mayoría la incorporación del sistema rural al organismo operador. Con este acto la asamblea cedió también la infraestructura y quedó disuelto el comité del agua. Después el SAPAL instaló una mesa de contrataciones en la comunidad que a su vez dio paso a la incorporación oficial de la comunidad a través del diagnóstico y reparación de infraestructura y la instalación de medidores en las viviendas.

Tras el cambio de gestión, en general los habitantes se sienten satisfechos con el servicio, aun cuando el costo de la cuota de SAPAL representa un aumento significativo para su economía familiar, hecho que influye para modificar el uso del agua en las actividades domésticas. A cuatro meses de la incorporación, la población continuaba pagando su contrato de ochocientos pesos por vivienda, que había sido diferido a pagos mensuales con cargo a su recibo. El pago mensual que hacía era de aproximadamente doscientos cincuenta pesos (la suma del consumo más el pago mensual del contrato). Además de que, una vez que se hubo incorporado la administración del agua al SAPAL, la población se dio cuenta de los falsos argumentos que algunos líderes estuvieron divulgando para evitar que la comunidad se incorporara al nuevo sistema.

Ladrilleras del Refugio es ahora una comunidad más integrada a la ciudad de León, lo que sus habitantes ven como una señal de progreso. Por su parte, los ladrilleros están preocupados por encontrar una nueva fuente de empleo que les permita subsistir ante el embate de la urbanización sobre su actividad económica.

\section{Conclusiones}

El concepto de lo metropolitano es una escala de análisis que integra espacios heterogéneos: urbanos, periurbanos y rurales habitados por actores con intereses y necesidades particulares. Es imprescindible comprender los cambios en las funciones de los territorios a consecuencia del proceso de urbanización, pues éste está vinculado a la gestión y a la disponibilidad de los recursos y sus posibles efectos negativos o positivos para los diferentes actores.

Los casos considerados en esta investigación permiten analizar el proceso de transición de las comunidades, entendidas como espacios rurales y periurbanos 
que se integran a lo urbano a partir de un esquema municipalizado que concentra la gestión de los recursos naturales. Este proceso puede o no interferir con los intereses y las motivaciones de los habitantes de tales espacios, al mismo tiempo que puede producir cualquier tipo de externalidades.

La discusión alrededor de la incorporación al SAPAL se centra en la percepción de los habitantes sobre quién debe administrar el agua, aun cuando las partes involucradas sostengan diferentes argumentos: el despojo de los recursos propios de la comunidad por parte de los miembros del comité; el cobro de cuotas más altas por parte de los habitantes; garantizar el acceso universal al agua por parte del organismo operador.

La revisión de los casos de estudio permite inferir que las decisiones sobre la administración del agua en las comunidades rurales dependen de los comités, de un grupo de personas o incluso de sólo una persona que, con base en usos y costumbres, desempeñan sus funciones de gestión de manera ceremonial. La figura del comité del agua no es imparcial, sino que sus múltiples roles sociales en la comunidad tienen una influencia importante en la ejecución de sus tareas, lo cual se hace evidente en la tolerancia a la cartera vencida y a los cortes de suministro de agua arbitrarios de los que se queja la población.

Los comités de agua que se estudiaron han desempeñado el papel de figura de autoridad y poder en la comunidad, posición que ha sido aprovechada por grupos políticos que ejercen presión sobre los delegados de la comunidad y otras figuras de liderazgo, situación que ha ocasionado la generación de conflictos.

La falta de trasparencia en el manejo de los recursos financieros es uno de los temas más sensibles sobre la gestión comunitaria del agua. La ausencia de mecanismos que garanticen la rendición de cuentas incide en el deterioro de las relaciones de confianza entre habitantes y comités; también entorpece la acción colectiva, cuya función está orientada a tomar decisiones acertadas para una adecuada gobernanza del agua.

El nivel de confianza entre usuarios y comités, así como los conflictos y la falta de resultados en la autogestión que éstos provocan, determinan la intervención del SAPAL en el proceso de municipalización del agua en estas comunidades.

En Ladrilleras del Refugio, por ejemplo, la escasez de agua ahondó la desconfianza de los usuarios de la red doméstica hacia los miembros del comité del agua, cuyo conflicto tuvo una transitoria solución en la incorporación de la gestión del agua comunitaria a la gestión municipal. La Laborcita, por su parte, es una comunidad que basó la solución del conflicto por la disputa del agua con el gobierno local en las relaciones de confianza que se han establecido con los miembros del comité, de ahí que rechazó la incorporación para continuar con un sistema de autogestión; y, por último, Loza de los Padres, que rechazó la incorporación en medio de un conflicto más severo y una situación de desconfianza más intensa hacia las autoridades municipales que hacia el comité del agua.

La revisión de estos tres casos de la gestión comunitaria del agua permite concluir que, ante el inminente fenómeno de urbanización en el país, es ineludible atender los efectos socio-ambientales que producirá la concentración de 
demanda de recursos naturales para sostener las ciudades. En este sentido, es posible desarrollar sistemas alternativos de gestión como medida para solucionar el conflicto a partir del fortalecimiento de las relaciones de confianza, pues estos sistemas serán indispensables para una buena gobernanza del agua en aquellas regiones que aún tienen la oportunidad de gestionar con autonomía el vital líquido.

\section{Referencias}

Aguilera, K. (2009). Una nota sobre el nobel de economía Elinor Ostrom. Economía Crítica, 8, 4-8.

Alguacil, J. (2012). Metrópoli versus Ciudad. En R. Valladares, La ciudad. Antecedentes y nuevas perspectivas (pp. 145-238). Guatemala: Universidad de San Carlos.

Álvarez-Castañón, L. (2016). La inversión extranjera automotriz y el potencial de reconversión tecnológica de la industria local manufacturera en Guanajuato. En J. Rodríguez, L. Álvarez, D. Tagle y J. Coronado (coords.), Desarrollo desde lo local y dinámicas territoriales (pp. 163-190). México: Universidad de Guanajuato y Editorial Fontamara.

Arrojo, P. (2006). El reto ético de la nueva cultura del agua. Funciones, valores y derechos en juego. España: Paidós.

Ávila, H. (2009). Periurbanización y espacios rurales en la periferia de las ciudades. Estudios Agrarios, 15(40), 93-123. Recuperado de http://www.pa.gob. $\mathrm{mx} / \mathrm{publica} / \mathrm{rev}$ 41/ANALISIS/7\%20HECTOR\%20AVILA.pdf

Ávila, H. (coord.) (2005). Lo urbano-rural, ¿nuevas expresiones territoriales? México: Centro Regional de Investigaciones Multidisciplinarias (CRIM) y Universidad Nacional Autónoma de México (UNAM).

Barkin, D. (2014). La crisis del agua en León: un proceso cuidadosamente gestionado. En D. Tagle (coord.), La crisis multidimensional del agua en la ciudad de León (pp.139-148). Guanajuato: Miguel Ángel Porrúa.

Barkin, D. (coord.) (2006). La gestión del agua urbana en México. México: Universidad de Guadalajara y Asociación Nacional de Empresas de Agua y Saneamiento.

Bazant, J. (2015). Proceso de transformación territorial en las periferias urbanas. En G. Olivera (coord.), La urbanización social y privada del ejido. Ensayos sobre la dualidad del desarrollo urbano en México (pp. 75-102). México: UNAM.

Berger, P., y Luckmann, T. (2003). La construcción social de la realidad. Buenos Aires: Amorrortu Editores.

Blomquist, W., y Ostrom, E. (1992). Capacidad institucional y solución al dilema de los recursos de propiedad común. En F. Aguilera (coord.). Economía del agua. Madrid: Ministerio de agricultura, pesca y alimentación.

Cadena, C., Cruz, G., y Maass, S. (2011). Agua potable y redes de política pública. Entre la captura y la exclusión. Caso de los comités independientes de agua potable en el municipio de Toluca. En F. Porras (coord.), Gobernanza y 
redes de política pública en espacios locales de México (pp. 197-244). México: Instituto de Investigaciones Dr. José María Luis Mora.

Caldera, A. (2011). Una ciudad con sed: acción pública y resultados para hacer frente a la crisis del agua en León, Guanajuato, México. En S. Suárez et al. (coords.), Dinámica local-global. Dilemas socio territoriales en el centro de México (pp. 45-68). Buenos Aires: Libros en Red.

Caldera, A., y Tagle, D. (2015). La acción pública y la construcción social de conflictos por el agua entre cuencas vecinas: el caso de la gestión del agua en León, Guanajuato. (Working Paper). Waterlat-Gobacit Network. Thematic Area SeriesSatcth TA6 Basins and Hydrosocial Territories, vol. 2, Núm. 1. Recuperado de http:// waterlat.org/WPapers/WPSATCTH21.pdf

Canabal, B. (2005). Actores rural-urbanos: proyectos e identidades. En H. Ávila (coord.), Lo urbano-rural, ¿nuevas expresiones territoriales? (pp. 161-178). México: UNAM y CRIM.

Cirelli, C. (2004). Agua desechada, agua aprovechada. Cultivando en las márgenes de la ciudad. México: El Colegio de San Luis.

Cruz, M. S. (2005). Las dimensiones rural y urbana en los espacios periféricos metropolitanos. El caso de la Zona Metropolitana del Valle de México. En H. Ávila (coord.), Lo urbano-rural, ¿nuevas expresiones territoriales? (pp. 179206). México: UNAM y CRIM.

Delgado, J. (2003). Transición rural-urbana y oposición campo-ciudad. En A. Aguilar (coord.), Urbanización, cambio tecnológico y costo social. El caso de la región centro de México (pp. 73-113). México: UNAM y Miguel Ángel Porrúa.

Díaz, M. (2017). El territorio como poder en el espacio social de la gestión comunitaria del agua. En M. Torregrosa (coord.), El conflicto del agua. Política, gestión, resistencia y demanda social (pp. 297-320). México: Facultad Latinoamericana de Ciencias Sociales (FLACSO).

Escobar, C. (2017). Las presidencias de comunidad en tres municipios del estado de Tlaxcala. En M. Torregrosa (coord.). El conflicto del agua. Política, gestión, resistencia y demanda social (pp. 277-296). México: FLACSO.

Fontecilla, A. (2015). Las representaciones sociales del agua y las posibilidades de una "ciudadanía hídrica": el caso de Naolinco y Miahuatlán en Veracruz. En Memoria del Congreso de la Red Nacional de Investigación Urbana.

Galindo, E., y Palerm, J. (2016). Sistemas de agua potable rurales. Instituciones, organizaciones, gobierno, administración y legitimidad. Tecnología y ciencias del agua, 7(2), 17-34.

García, M. (2010). Transformaciones urbanas de León. Siglo XX. México: Tlacuilo.

García, M. (2019). La ciudad histórica de León. Guanajuato: Tlacuilo.

Garrocho, C. (2013). Dinámica de las ciudades de México en el siglo XXI: cinco vectores clave para el desarrollo sostenible. México: El Colegio Mexiquense y CONAPO.

Geertz, C. (2003). La interpretación de las culturas. España: Gedisa.

Grammont, H. (2015). Prólogo. En H. Ávila (coord.), Lo urbano-rural, ¿nuevas expresiones territoriales? (pp. 11-18). México: CRIM y UNAM. 
Hatch-Kuri, G. (2017). Agua subterránea en México: retos y pendientes para la transformación de su gestión. En R. Pacheco-Vega (coord.), El Agua en México. Actores, sectores y paradigmas para una transformación social-ecológica (pp. 149-170). México: Friedrich Ebert Stiftung.

Hernández, J. (2019). Efectos de la urbanización en la gestión del agua en las zonas periurbanas. El caso de la Zona Metropolitana de León, Guanajuato (tesis de maestría). México: Universidad Autónoma Metropolitana-Azcapotzalco.

Instituto Nacional de Estadística y Geografía (INEGI). (1990). XI Censo de Población y Vivienda 1990. México: INEGI. Recuperado de https://www.inegi.org. $\mathrm{mx} /$ programas/ccpv/1990/default.html

Instituto Nacional de Estadística y Geografía (INEGI). (2000) XII Censo de Población y vivienda 2000. México: INEGI. Recuperado de https://www.inegi.org. $\mathrm{mx} /$ programas/ccpv/2000/default.html

Instituto Nacional de Estadística y Geografía (INEGI). (2010). Censo de Población y Vivienda. México: INEGI. Recuperado de https://www.inegi.org.mx/ programas/ccpv/2010/default.html

Instituto Nacional de Estadística y Geografía (INEGI). (2018). Cartografías. México: Recuperado de https://www.inegi.org.mx/app/mapas/

Jalomo, F., y Martí, D. (2016). Taxonomía de modelos de gestión urbana del agua: experiencias de diversas latitudes y conclusiones aplicables al caso mexicano. Tecnogestión: Una Mirada al Ambiente, 13(1). Recuperado de https: / / revistas.udistrital.edu.co/index.php/tecges/article/view/12129

Les Ateliers. (2013). Taller internacional de diseño urbano. León: IMPLAN.

Lozano, G. (2014). La crisis del agua en León: claves para su comprensión. En D. Tagle (coord.), La crisis multidimensional del agua en la ciudad de León (pp. 87-102). Guanajuato: Miguel Ángel Porrúa.

Maceira, L. (2011). Interdisciplinariedad y etnografía. Reflexiones de una outsider de la antropología. Ankulegi, 15, 115-125. Recuperado de https:// aldizkaria.ankulegi.org/index.php/ankulegi/article/view/43/125

Martínez, E., y Suárez, S. (2015). Reconfiguración del espacio y desarrollo humano y territorial en la región metropolitana de León, Guanajuato. En H. Ávila (coord.), La ciudad en el campo (pp. 225-276). México: UNAM.

Mata, S. (2009). Planeación, irregularidad y expansión urbanas en León, Gto. en los últimos 30 años (tesis de maestría). Universidad Autónoma Metropolitana- Azcapotzalco, Ciudad de México.

Méndez, M. (2005). Contradicción, complementariedad e hibridación en las relaciones entre lo rural y lo urbano. En H. Ávila (coord.), Lo urbano-rural, ¿nuevas expresiones territoriales? (pp. 87-122). México: UNAM y CRIM.

Merino, L. (2014). Perspectiva sobre la gobernanza de los bienes y la ciudadanía en la obra de Elinor Ostrom. Revista mexicana de sociología, 76(Núm. Especial), 77-104.

Municipio de León. (1994). Reglamento de los sistemas rurales de agua y saneamiento de las comunidades rurales del municipio de León, Guanajuato. León, Guanajuato, México. 
Municipio de León. (1996). Reglamento del Sistema de Agua Potable y Alcantarillado de León. León, Guanajuato, México.

Municipio de León. (2010). Reglamento de los servicios de agua potable, alcantarillado y saneamiento para el municipio de León, Guanajuato. León, Guanajuato, México.

Municipio de León. (2017). Reglamento de los servicios de agua potable, alcantarillado y tratamiento para el municipio de León, Guanajuato. León, Guanajuato, México.

Ostrom, E. (2011 [1990]). El gobierno de los bienes comunes. México: Fondo de Cultura Económica.

Pacheco-Vega, R. (2017). El megaproyecto de la presa El Zapotillo como nodo centroidal de conflicto intratable. Un análisis desde la ecología política. Espiral. Estudios sobre Estado y Sociedad, 24(69), 193-229. doi: 10.32870/ espiral.v24i69.5283

Ramírez, B. (2005). Miradas y posturas frente a la ciudad y el campo. En H. Ávila (coord.), Lo urbano-rural, ¿nuevas expresiones territoriales? (pp. 61-86). México: UNAM y CRIM.

Ramírez, B. (2006). Del funcionalismo industrial al funcionalismo de servicios: ¿la nueva utopía de la metrópoli postindustrial del Valle de México? EURE, 32(95), 61-74. Recuperado de https://repositorio.uc.cl/bitstream/handle/11534/4063/000465431.pdf?sequence=1

Rodríguez, J. A. , y Caldera, A. (2013). Crecimiento económico y desarrollo local en la región Centro-Bajío de México. Quivera. Estudios Territoriales, 15, 3759. Recuperado de http://ri.uaemex.mx/handle/20.500.11799/67085

Rodríguez, J. A., Caldera, A., y D. Tagle. (2016). Nuevas precisiones para la medición del desarrollo humano. Planteamiento desde la escala microterritorial. Equilibrio Económico. Revista de Economía, Política y Sociedad, 12(2), 161-186.

Sistema de Agua Potable y Alcantarillado de León (SAPAL). (2012). SAPAL: trayectoria y futuro. México: SAPAL.

Sistema de Agua Potable y Alcantarillado de León (SAPAL). (31 de enero de 2018). SAPAL. Obtenido de Sala de Prensa: www.sapal.gob.mx Recuperado de http://www.sapal.gob.mx/noticia/443/70

Sobrino, J. (2003). Competitividad de la ciudades en México. México: El Colegio de México.

Sobrino, J. (2011). La urbanización en el México contemporáneo. Reunión de expertos sobre: población, territorio y desarrollo sostenible. Chile: CEPAL. Recuperado de https://www.cepal.org/sites/default/files/events/files/jaime_sobrino.pdf

Suárez, S., Martínez, E., y García, A. (2015). La dinámica económica y cultural de la zona metropolitana de León, Guanajuato: desafíos para el desarrollo humano y territorial. México: Juan Pablos Editor.

Tagle, D. (2016). Discrecionalidad y permisividad en la gestión del agua en León, Guanajuato: ausencia del derecho humano al agua y deterioro ambiental. En J. Rodríguez, L. Álvarez, D. Tagle, y J. Coronado (coords.), Desarrollo desde lo local y dinámicas territoriales (pp.201-232). México: Fontamara. 
Tagle, D., Caldera, A. , y Fuente, M. (2019). Normatividad, gestión pública y ambientalismo de mercado en México. Un análisis desde los proyectos políticos (2012-2018). Tecnología y Ciencias del Agua, 10(2), 1-34. doi: 10.24850/j-tyca-2019-02-01

Tagle, D., Caldera, A., y Rodríguez, J. (2017). Complejidad ambiental en el Bajío Mexicano: implicaciones del proyecto civilizatorio vinculado al crecimiento económico. región y sociedad, 29(68). doi: 10.22198/rys.2017.68. a873 